Research Article

\title{
Verification of CENDL-3.2 Nuclear Data on VENUS-3 Shielding Benchmark by ARES Transport Code
}

\author{
Jiaju Hu, Bin Zhang $\mathbb{D}^{\text {, }}$, Zhiwei Zong, Cong Liu, and Yixue Chen \\ School of Nuclear Science and Engineering, North China Electric Power University, Beijing 102206, China \\ Correspondence should be addressed to Bin Zhang; zhangbin@ncepu.edu.cn
}

Received 20 October 2020; Accepted 27 January 2021; Published 5 February 2021

Academic Editor: Arkady Serikov

Copyright ( 2021 Jiaju Hu et al. This is an open access article distributed under the Creative Commons Attribution License, which permits unrestricted use, distribution, and reproduction in any medium, provided the original work is properly cited.

\begin{abstract}
The recently released CENDL-3.2 nuclear data library is deemed as an important achievement in the field of nuclear data research in China. To verify the applicability of the library to the shielding calculation of PWR and analyze the influence of multigroup cross-section parameters on the shielding calculation, ARES-MACXS module is used to process the MATXS format multigroup library based on CENDL-3.2 to generate multigroup working cross sections for PWR shielding calculation. VENUS-3 experimental facility has a clear and complete geometry. It is often used to test the ability of the advanced transport calculation method of calculating RPV fast neutron flux and to evaluate the accuracy of cross-section library. Different cross-section parameters are chosen for ARES to calculate VENUS-3 benchmark, and equivalent neutron flux of ${ }^{58} \mathrm{Ni}(\mathrm{n}, \mathrm{p}){ }^{58} \mathrm{Co},{ }^{115} \mathrm{In}\left(\mathrm{n}, \mathrm{n}^{\prime}\right){ }^{115 \mathrm{~m}} \operatorname{In}$ and ${ }^{27} \mathrm{Al}(\mathrm{n}, \alpha)$

${ }^{24} \mathrm{Na}$ detectors is calculated according to the data provided by the benchmark report. The numerical results demonstrate that almost all the relative deviations between the calculated results and the experimental results are within $20 \%$, which satisfies the requirement of shielding calculation. CENDL-3.2 is suitable for PWR shielding calculation. The comparison of various crosssection parameters results indicates that multigroup cross-section parameters have large effects on the transport calculation results.
\end{abstract}

\section{Introduction}

With the rapid development of computer science and technology and improved understanding of transport calculation theory, the discrete ordinates method $\left(S_{N}\right)$ becomes one of the most efficient and common tools for radiation shielding calculations, especially for neutron shielding calculations [1]. As a part of deterministic computation, the accuracy of the multigroup cross-section library becomes more and more important to improve the accuracy of transport calculation results. With the development of China's nuclear industry, the Chinese Evaluated Nuclear Data Library (CENDL) [2] has been one of the five internationally recognized mainstream nuclear databases since 1991 . The library is highly recognized by the international nuclear data community and widely used in scientific research and engineering calculation. The latest version of the Chinese Evaluated Nuclear Data Library, CENDL3.2, was released on June 12, 2020. The CENDL-3.2 evaluates 272 nuclides compared with 240 in the previous version, with data types and quality greatly improved. The neutron reaction data for 134 nuclides have been re-evaluated and tested, including ${ }^{6} \mathrm{Li},{ }^{7} \mathrm{Li},{ }^{56} \mathrm{Fe},{ }^{235} \mathrm{U},{ }^{238} \mathrm{U},{ }^{239} \mathrm{Pu},{ }^{240} \mathrm{Pu}$, and all essential nuclides in nuclear energy and nuclear technology applications. To verify the applicability of the evaluated nuclear data library for VENUS-3 international benchmark [3-5], NJOY [6] was used to generate 199 groups MATXS-format multigroup library based on CENDL-3.2. Various combinations of multigroup cross-section parameters are used for ARES-MACXS to generate multigroup working cross-section library. ARES $[7,8]$ is used for three-dimensional deterministic transport calculations. Equivalent neutron flux of multiple reaction channels are calculated and compared with experimental results. In order to analyze the influence of multigroup cross section on VENUS-3 benchmark, the calculation results of various cross-section parameters are compared.

The rest of the paper is organized as follows. Section 2 introduces the multigroup deterministic discrete ordinates transport code ARES and VENUS-3 benchmark. Section 3 
compares the multigroup calculation results based on CENDL-3.2 with experimental results. Section 4 analyzes the influence of different parameters of multigroup cross sections on VENUS-3 benchmark. Section 5 gives the conclusions.

\section{Introduction of ARES Code and VENUS-3 Benchmark}

2.1. Discrete Ordinates Transport Code ARES. In order to obtain accurate shielding calculation results, ARES was independently developed by North China Electric Power University (NCEPU). ARES is a multidimensional parallel discrete ordinate $\left(S_{N}\right)$ particle transport code system to solve the linear Boltzmann transport equation. The code system can be applied to a wide variety of radiation shielding calculations and reactor physics analysis. To solve special shielding problems such as deep penetration, several computing modules were developed. The ARES code system consists of ARES_PRE, ARES_MACXS, DONTRAN1D, DONTRAN2D, DONTRAN3D, RAY2D, RAY3D, and ARES_POST, which contain preprocessing, multigroup crosssection generation, one-dimensional transport calculation, two-dimensional transport calculation, three-dimensional transport calculation, two-dimensional ray effect elimination, three-dimensional ray effect elimination, and postprocessing.

ARES-MACXS is a multigroup cross-section generation module and is used to provide an accurate multigroup cross section related to the problem of ARES. The module processes MATXS-format multigroup library and generates multigroup cross sections related to the computational problem. The module has the function of resonance processing, temperature interpolation, neutron-photon coupling, upscattering processing, transport correction, and collapse group. The process of ARES-MACXS module is shown in Figure 1. This module can directly provide multigroup cross section for transport calculating module or generate the anisn or anisnb format multigroup cross-section library for other codes.

Self-shielding correction is the core function of the module. ARES-MACXS uses the Bondarenko method, which is based on the narrow resonance approximation. It is assumed that the energy lost by each neutron collision is far less than the formant width of the target nucleus. The process of self-shielding correction is shown in Figure 2. Using the Bondarenko method [9] for resonance calculation, self-shielding factor is defined as follows:

$$
f_{x, i, g}\left(\sigma_{0}, T\right)=\frac{\sigma_{x, i, g}\left(\sigma_{0}, T\right)}{\sigma_{x, i, g}(\infty, T)}
$$

where $x$ is the calculated reaction channel, $i$ is the calculated nuclide, and $g$ is the energy group.

The self-shielding factor is a function of temperature $T$ and background cross section $\sigma_{0}$. Therefore, to obtain more accurate self-shielding factor, the interpolation method is very important. Linear interpolation is a commonly used interpolation method in the world, which is efficient in the calculation and does not introduce nonphysical oscillation.
However, there is no strict linear relation between temperature, background cross section, and self-shielding factor. In order to improve the accuracy of the interpolation method, the ARES-MACXS module adopts the exponential interpolation method, in which the interpolation curve can always satisfy three monotone interpolation points [10]. For temperature interpolation, the interpolation equation is

$$
f(T)=f_{i}+\frac{T^{p}-T_{i}^{p}}{T_{i+1}^{p}-T_{i}^{p}}\left(f_{i+1}-f_{i}\right),
$$

where $f$ is the Bondarenko factor, $i$ is the index of interpolation points, and $p$ is constant, which is determined by three interpolation points.

This method can accurately interpolate temperature. However, for background cross-section interpolation, the situation shown in Figure 3 [10] may occur. Two different curves may appear in segments 3-4. To solve this problem, using functions instead of constant $p$, the interpolation equation for the background cross section is obtained [10]:

$$
f_{T}\left(\sigma_{0}\right)=f_{T}\left(\sigma_{1}\right)+\frac{\sigma^{q(\sigma)}-\sigma_{1}^{q(\sigma)}}{\sigma_{2}^{q(\sigma)}-\sigma_{1}^{q(\sigma)}}\left[f_{T}\left(\sigma_{2}\right)-f_{T}\left(\sigma_{1}\right)\right]
$$

where $q(\sigma)$ satisfies the following relationship [10]:

$$
q(\sigma)=q\left(\sigma_{1}\right)+\frac{\sigma-\sigma_{1}}{\sigma_{2}-\sigma_{1}}\left(q\left(\sigma_{2}\right)-q\left(\sigma_{1}\right)\right)
$$

In this way, a unique interpolation curve can be obtained, and a more accurate self-shielding cross section can be obtained.

2.2. VENUS-3 Benchmark. The VENUS experiment is located at the National Nuclear Technology Center in Belgium. It was built in 1964 and was modified and adjusted three times in 1967, 1980, and 1982. After the year 1988, the experimental device was used in the LWR-PVS benchmark experiment. The VENUS-3 reactor has a clear and perfect geometry and conforms to modern standard PWR pressure vessel construction conditions. Therefore, the VENUS-3 fixed source benchmark is used to test the ability of advanced transport calculation method to calculate the fast neutron flux of pressure vessels and to evaluate the accuracy of multigroup cross-section library.

The VENUS-3 reactor is a low-flux thermal neutron reactor with a total reactor length of $168 \mathrm{~cm}$. The core is a "cross" structure and consists of three types of fuel rods: $\mathrm{UO}_{2}$ rods with stainless steel cladding at a concentration of $4 \%$, $\mathrm{UO}_{2}$ rods with zirconium tin alloys cladding at a concentration of $3.3 \%, \mathrm{UO}_{2}$ rods with zirconium tin alloys cladding at a concentration of $3.3 \%$, and iron rods (PLSA) with zirconium tin alloys cladding at a concentration of $3.3 \%$. The spacing between each fuel rod is $1.26 \mathrm{~cm}$, the rod arrangement is $15 \times 15$, and the height of the fuel active zone was $50 \mathrm{~cm}$. A quarter of the core consists of 639 fuel rods and 11 control rods. The three types of fuel rods are 369, 195, and 75 , respectively. Table 1 lists the material composition of some important devices. 


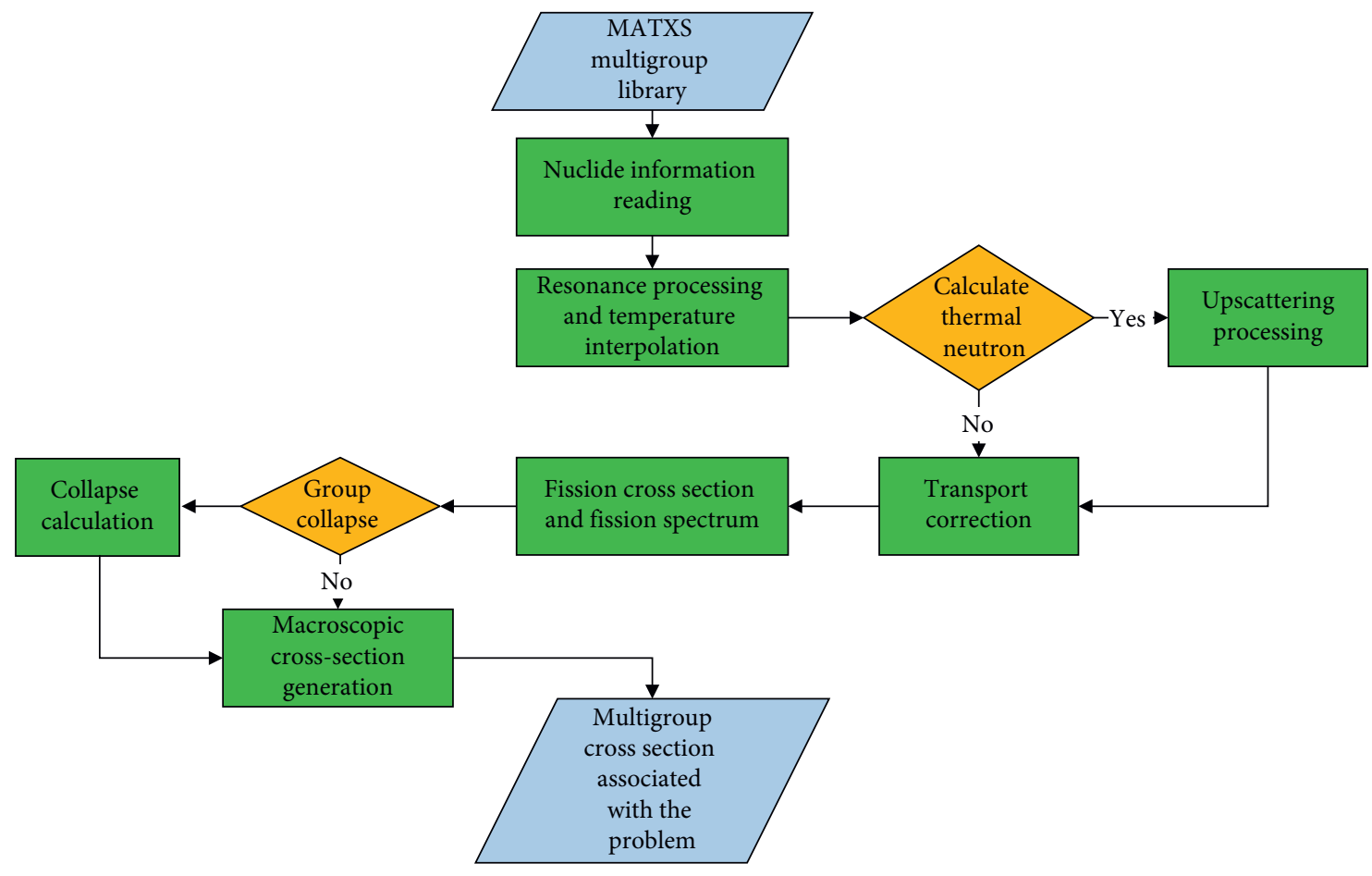

Figure 1: Processing procedure of ARES-MACXS.

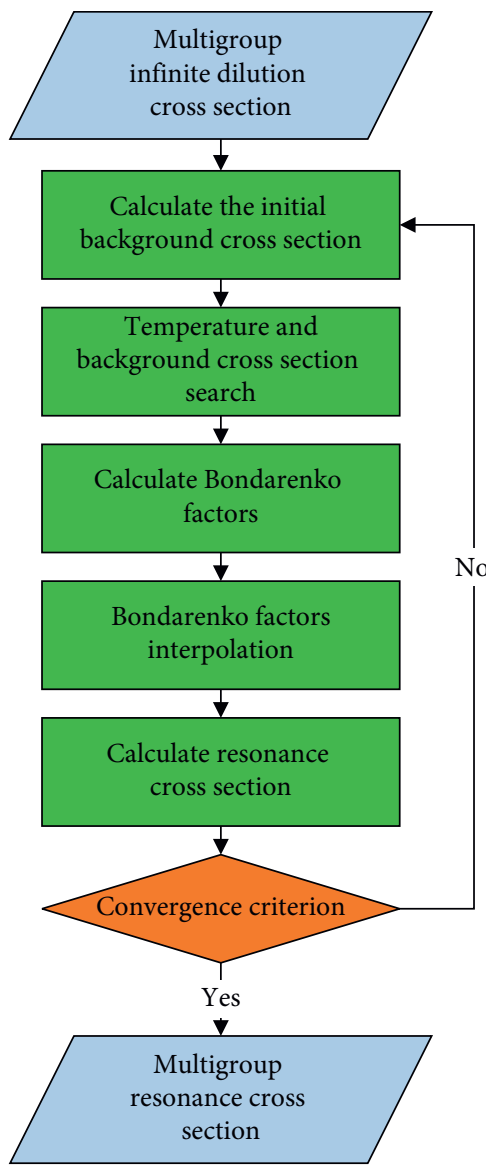

Figure 2: Processing procedure of self-shielding correction.

\section{Comparison of ARES Results with Experimental Results}

3.1. Calculation Model and Multigroup Cross Section. To obtain a more accurate transport calculation, the area between the central hole of the VENUS-3 reactor and the inner wall of the stainless steel sandwich has been fully modeled by ARES. Considering the symmetry of the reactor, $1 / 4$ of the reactor core is calculated. The negative $X$-axis and $Y$-axis negative boundary of the model is set as a reflection boundary, and the rest is set as a vacuum boundary. The composition content of stainless steel jacket and other areas far away from the core source area has little influence on the neutron flux of the core. For calculation efficiency, these areas are not considered in the modeling. The actual modeling height was $84.5 \mathrm{~cm}$, and each component was partitioned for modeling. The structure of vertical core upper and lower grid area is staggered with the reflection layer area, which has little influence on the neutron movement in the horizontal core source area. Accurate modeling will increase the number of grids and occupy the majority of computing resources, so the mixing process is carried out according to the volume fraction of each component in the modeling.

The horizontal and axial models are shown in Figure 4. The grid size of the core area in the $X$ and $Y$ directions is $1.26 \mathrm{~cm}$, and the grid size of the noncore area is $2 \mathrm{~cm}$. During the modeling, the grid size of the axial core area is the same as the axial size of the core normalized relative power distribution data provided by the benchmark, and the grid size of the rest of the areas are set as $4 \mathrm{~cm}$. The whole core is $66 \mathrm{~cm}$ in the $X$ direction, $66 \mathrm{~cm}$ in the $Y$ direction, and 


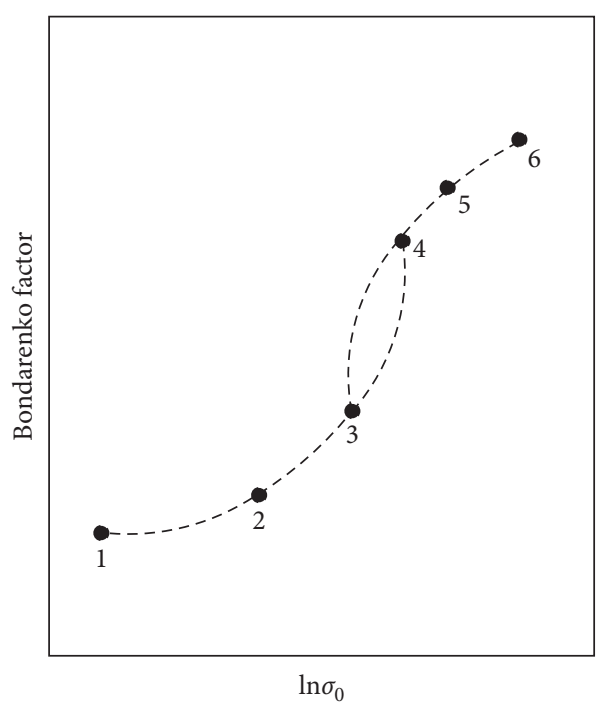

Figure 3: "S-shape" of $\sigma_{0}$ variation of Bondarenko factor.

TABLE 1: VENUS-3 benchmark device material composition.

\begin{tabular}{lc}
\hline Location & Nuclide composition \\
\hline \multirow{2}{*}{ /0 fuel pin } & $\mathrm{U}, \mathrm{O}, \mathrm{Sn}$ \\
& $\mathrm{Fe}, \mathrm{Cr}, \mathrm{Zr}, \mathrm{H}$ \\
\hline \multirow{3}{*}{ Inner and outer baffle } & $\mathrm{C}, \mathrm{Mn}, \mathrm{P}$ \\
& $\mathrm{S}, \mathrm{Si}, \mathrm{Cr}$ \\
PLSA & $\mathrm{Ni}, \mathrm{Mo}, \mathrm{Co}, \mathrm{Fe}$ \\
\hline \multirow{3}{*}{ Barrel } & $\mathrm{C}, \mathrm{Mn}$ \\
& $\mathrm{P}, \mathrm{S}$ \\
& $\mathrm{C}, \mathrm{Mn}, \mathrm{P}$ \\
Pyrex & $\mathrm{S}, \mathrm{Si}, \mathrm{Cr}$ \\
& $\mathrm{Ni}, \mathrm{Mo}, \mathrm{Co}$ \\
$\mathrm{Fe}, \mathrm{N}$ \\
\hline \multirow{2}{*}{ Neutron pad } & $\mathrm{Si}, \mathrm{O}, \mathrm{B}$ \\
& $\mathrm{Al}, \mathrm{Fe}, \mathrm{Na}$ \\
$\mathrm{K}, \mathrm{C}, \mathrm{Mn}$ \\
Jacket inner wall & $\mathrm{Cr}, \mathrm{Ni}, \mathrm{Mo}, \mathrm{H}$ \\
\hline & $\mathrm{C}, \mathrm{Mn}, \mathrm{P}$ \\
& $\mathrm{S}, \mathrm{Si}, \mathrm{Cr}$ \\
& $\mathrm{Ni}, \mathrm{Mo}, \mathrm{Co}, \mathrm{Fe}$ \\
\hline $\mathrm{C}, \mathrm{Mn}, \mathrm{P}$ \\
$\mathrm{S}, \mathrm{Si}, \mathrm{Ce}$ \\
$\mathrm{Ni}, \mathrm{Mo}, \mathrm{Co}$ \\
$\mathrm{Fe}, \mathrm{N}$
\end{tabular}

$84.5 \mathrm{~cm}$ in the $Z$ direction. The overall model is divided into a $52 \times 54 \times 27$ grid with 75816 grids.

CENDL-3.2 Evaluated Nuclear Data Library is processed into MATXS-format multigroup cross-section library with VITAMIN-B7 energy group structure by NJOY, which contains 199 groups of neutrons. ARES-MACXS module processes MATXS library with a series of corrections to generate a multigroup working cross section associated with the VENUS-3 benchmark.

3.2. Comparison of Calculation Results. Detailed experimental measurements of ${ }^{58} \mathrm{Ni}(\mathrm{n}, \mathrm{p}){ }^{58} \mathrm{Co},{ }^{115} \mathrm{In}\left(\mathrm{n}, \mathrm{n}^{\prime}\right){ }^{115 \mathrm{~m}} \mathrm{In}$, and ${ }^{27} \mathrm{Al}(\mathrm{n}, \alpha){ }^{24} \mathrm{Na}$ reactions are given in the benchmark report. The reaction thresholds of the three detectors are $2.70 \mathrm{MeV}, 1.30 \mathrm{MeV}$, and $7.30 \mathrm{MeV}$, respectively. It was found that the three dosimetry results are, respectively, equivalent to the neutron flux above $3.0 \mathrm{MeV}, 1.0 \mathrm{MeV}$, and 8.0 MeV in the ${ }^{235} \mathrm{U}$ fission spectrum in the actual measurement. These detectors were used to accurately detect the fast neutron flux in each component region. A total of 386 detector monitoring points are set in the core, baffle, barrel, PLSA, and water gap area. There are 244, 104, and 38 monitoring points of the three kinds of detectors, respectively. The benchmark report introduces a new variable to describe the measured experimental value: equivalent fission flux, which is the ratio of reaction rate to ${ }^{235} \mathrm{U}$ fission spectrum-weighted average cross sections [11]. The calculation equation is

$$
\phi_{e q}^{d}=\frac{\sum_{g} \sigma_{g}^{d} \phi_{g}}{\sum_{g} \sigma_{g}^{d} \chi_{g}},
$$

where $\sigma_{g}^{d}$ is the reaction cross section of detector $d$ of the $g$ energy group, $\phi_{g}$ is the neutron flux of the $g$ energy group, and $\chi_{g}$ is the fission spectrum of the $g$ energy group.

The microcross sections of ${ }^{58} \mathrm{Ni}(\mathrm{n}, \mathrm{p}){ }^{58} \mathrm{Co},{ }^{115} \mathrm{In}\left(\mathrm{n}, \mathrm{n}^{\prime}\right)$ ${ }^{115 \mathrm{~m}} \mathrm{In}$, and ${ }^{27} \mathrm{Al}(\mathrm{n}, \alpha){ }^{24} \mathrm{Na}$ were obtained from the INDC(NDS) database. The average dose cross sections of the three reactions are $0.112407,0.191824$, and 0.000771 barns, respectively.

The benchmark calculation is carried out by the ARES transport code with 199 neutron groups multigroup crosssections. ARES-MACXS module generates the multigroup cross-sections with $\mathrm{P}_{3}$ Legendre expansion order, selfshielding correction, and Bell-Hansen-Sandmeier (BHS) transport approximation. The results of KASHIL-E70 [12] multigroup cross-section library based on ENDF/B VII.0 were used for comparison. Figures 5-7 show equivalent fission flux rations (calculated/experimental) of the ${ }^{58} \mathrm{Ni}(\mathrm{n}, \mathrm{p}){ }^{58} \mathrm{Co}$ detector, ${ }^{115} \operatorname{In}\left(\mathrm{n}, \mathrm{n}^{\prime}\right){ }^{115 \mathrm{~m}} \mathrm{In}$ detector, and ${ }^{27} \mathrm{Al}(\mathrm{n}, \alpha)^{24} \mathrm{Na}$ detector in different areas, respectively. The CENDL-3.2 average C/E results of the three detectors are $1.047,1.035$, and 0.921 , respectively. The CENDL-3.2 average $\mathrm{C} / \mathrm{E}$ results of the three detectors are $1.039,1.015$, and 0.947 , respectively. The trend of the results is the same as in the benchmark report [13]. Moreover, the calculation results at fuel pin have a good agreement with the experimental results, which are almost the same with ENDF/B VII.0 results. At other regions, CENDL-3.2 results have a slight difference with ENDF/B VII.0 results. The numerical results demonstrate that the relative deviation between the calculated results and the experimental values is all within $20 \%$ for the ${ }^{115} \operatorname{In}\left(n, n^{\prime}\right){ }^{115 m}$ In detector. The ${ }^{58} \mathrm{Ni}(\mathrm{n}, \mathrm{p}){ }^{58} \mathrm{Co}$ detector and ${ }^{27} \mathrm{Al}(\mathrm{n}, \alpha){ }^{24} \mathrm{Na}$ detector results' relative deviation is almost within $20 \%$ except for a few detector points, which satisfies the requirement of shielding calculation.

The results show that the transport calculation results using CENDL-3.2 library are acceptable compared to the experimental measurements, which is suitable for VENUS-3. Therefore, CENDL-3.2 can provide accurate cross-section data for the PWR shielding calculation. 


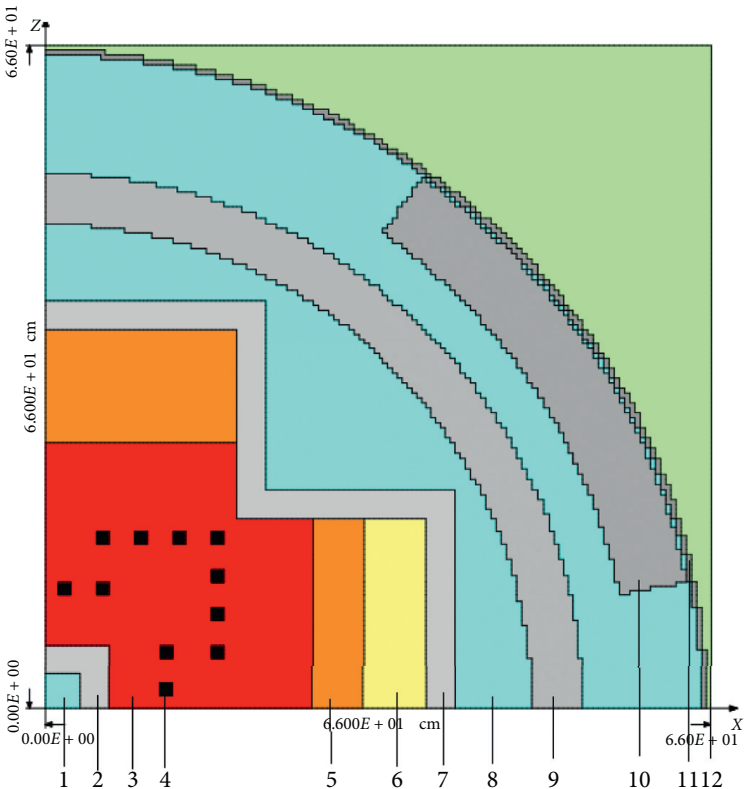

(a)

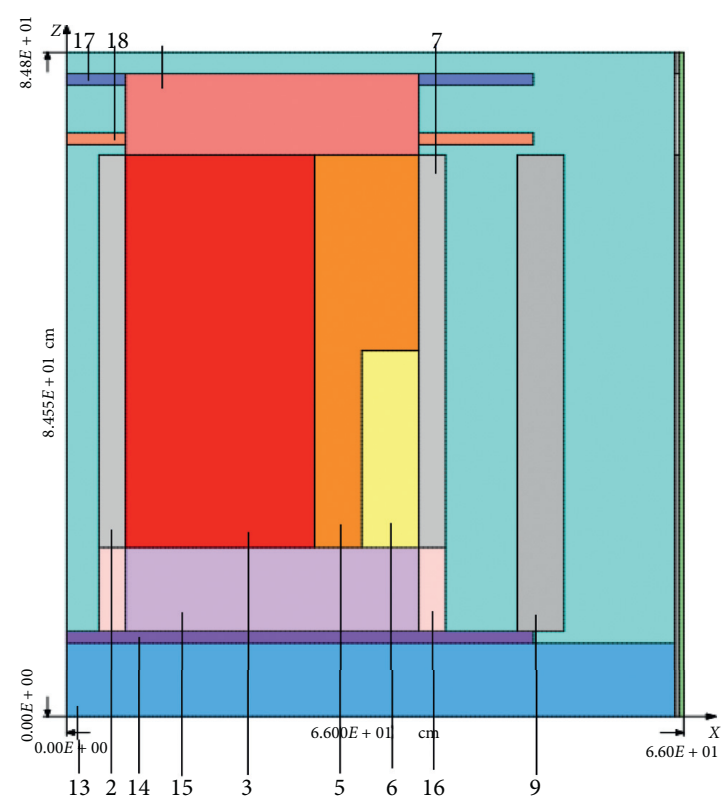

(b)

FIgURE 4: Sectional view of VENUS-3 model.

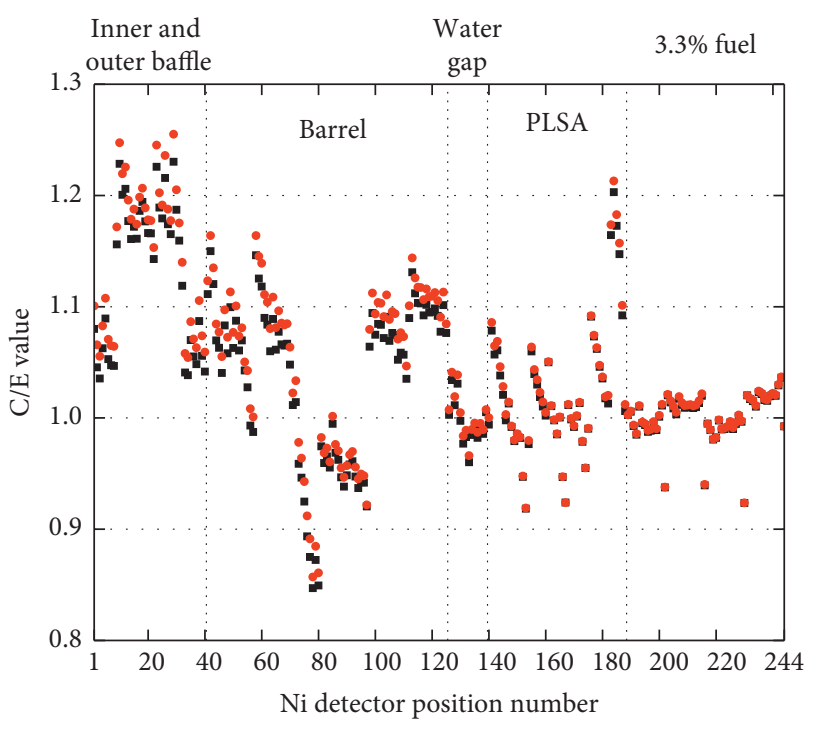

- ENDF/B VII.0 results

- CENDL-3.2 results

FiguRE 5: Equivalent fission flux ratios (calculated/experimental) of the ${ }^{58} \mathrm{Ni}(\mathrm{n}, \mathrm{p}){ }^{58}$ Co detector.

\section{Analysis of the Influence of Multigroup Cross Sections on VENUS-3 Benchmark}

As an important part of deterministic calculation, the accuracy of multigroup cross section has a great effect on the accuracy of the transport calculation. In order to analyze the influence of multigroup cross section on VENUS-3 benchmark transport calculation, different cross-section parameters are used to calculate the benchmark, and the influence of different cross section parameters on the calculation results is compared in the following part. The multigroup cross section is based on CENDL-3.2.

4.1. Influence of Broad-Group Structure on VENUS-3 Benchmark. For multigroup transport calculation, the finer energy group structure can describe the resonance peak of nuclides more exactly and can obtain the distribution of neutron scattering to different energies more accurately. However, the fine energy group structure will greatly increase the calculation time and reduce the calculation efficiency. For large engineering problems, this situation is even more serious. Therefore, in practical calculations, it is usually necessary to collapse the fine-group cross section to the broad group for transport calculation to improve the calculation efficiency.

The transport calculation is carried out by collapsing the VITAMIN-B7 [14] 199 fine-group structure to BUGLE-B7 [15] 47 broad-group structure and TEXT-10 [16] 30 broadgroup structure, respectively, to verify the influence of energy group structure on the calculation results of VENUS-3 benchmark. Figures $8-10$ are the comparisons of three detector results. For the ${ }^{58} \mathrm{Ni}(\mathrm{n}, \mathrm{p}){ }^{58} \mathrm{Co}$ detector, 47 broadgroup results are almost the same with 199 fine-group results. At the baffle and barrel regions, 30 broad-group results differ from the other two results. For the ${ }^{115} \operatorname{In}\left(n, n^{\prime}\right){ }^{115 m}$ In detector, three group structure results are basically the same, and the neutron group structure has little effect on the calculation results. For the ${ }^{27} \mathrm{Al}(\mathrm{n}, \alpha)^{24} \mathrm{Na}$ detector, the calculated results increase with the decrease of the number of energy groups. To improve the calculation efficiency and reduce calculation error as much as possible, BUGLE-B7 47 broad-group structure is appropriate for VENUS-3 transport calculation. The rest of the paper used the 47 group energy group structure for calculations. 


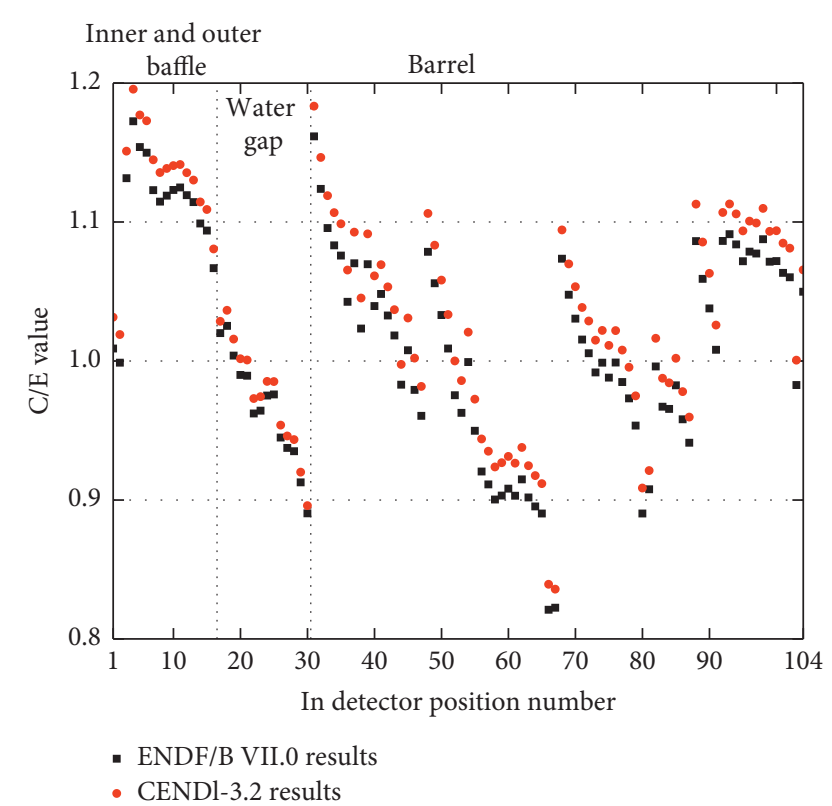

Figure 6: Equivalent fission flux ratios (calculated/experimental) of the ${ }^{115} \operatorname{In}\left(n, n^{\prime}\right)^{115 m}$ In detector.

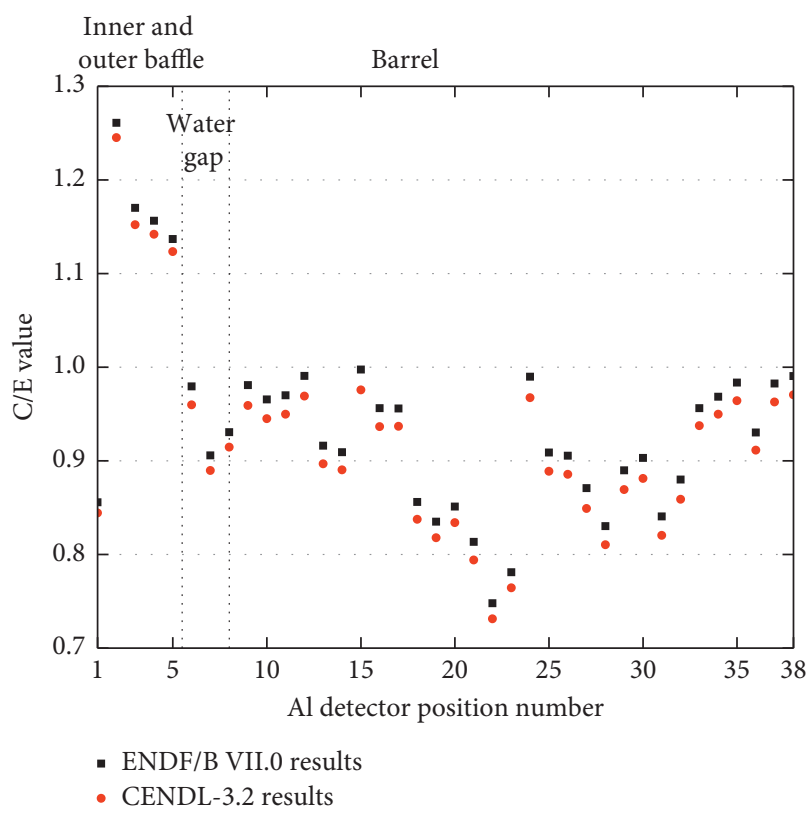

FIGURE 7: Equivalent fission flux ratios (calculated/experimental) of the ${ }^{27} \mathrm{Al}(\mathrm{n}, \alpha)^{24} \mathrm{Na}$ detector.

4.2. Influence of Self-Shielding Correction on VENUS-3 Benchmark. Self-shielding correction is an important method to reduce the error of multigroup cross section by energy discretization. Many nuclides have strong resonance in the shielding calculation. There are many self-shielding correction methods such as the equivalence theory, the hyperfine energy group method, and the subgroup method. The Bondarenko method is widely used in the shielding calculation because of its high computational efficiency and high accuracy. ARES-MACXS module uses this method generating resonance cross section.

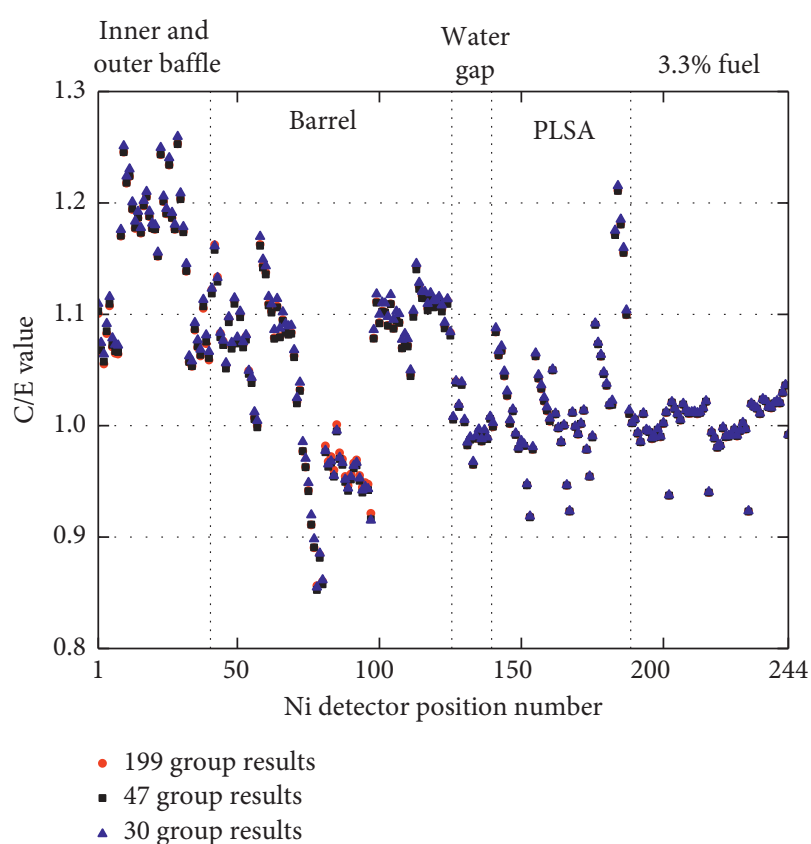

Figure 8: Comparison of group structure of the ${ }^{58} \mathrm{Ni}(\mathrm{n}, \mathrm{p}){ }^{58} \mathrm{Co}$ detector.

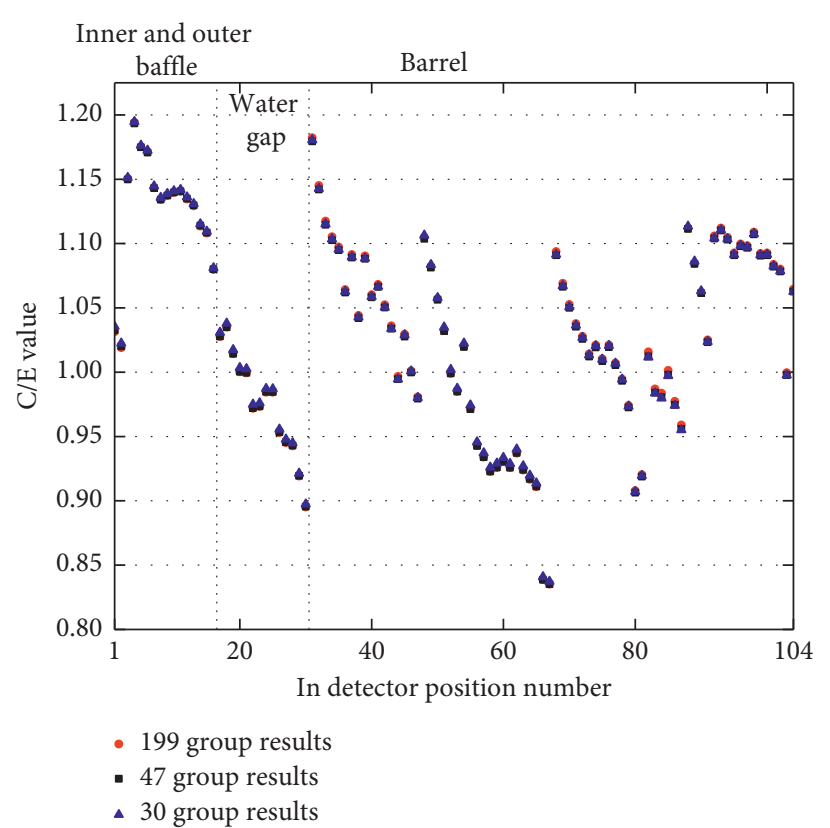

Figure 9: Comparison of group structure of the ${ }^{115} \operatorname{In}\left(n, n^{\prime}\right)^{115 m} \operatorname{In}$ detector.

To verify the influence of the method for VENUS-3 benchmark, the resonance and infinite dilution cross sections are used to calculate the benchmark, respectively. Figures 11-13 are the comparison of three detector results. The results show that the self-shielding correction has little effect for the ${ }^{58} \mathrm{Ni}(\mathrm{n}, \mathrm{p}){ }^{58} \mathrm{Co}$ detector and has no effect for the ${ }^{27} \mathrm{Al}(\mathrm{n}, \alpha){ }^{24} \mathrm{Na}$ detector. For the ${ }^{115} \mathrm{In}\left(\mathrm{n}, \mathrm{n}^{\prime}\right){ }^{115 \mathrm{~m}}$ In detector, self-shielding correction slightly increases the calculation results. The thresholds energy of the three detectors is higher 


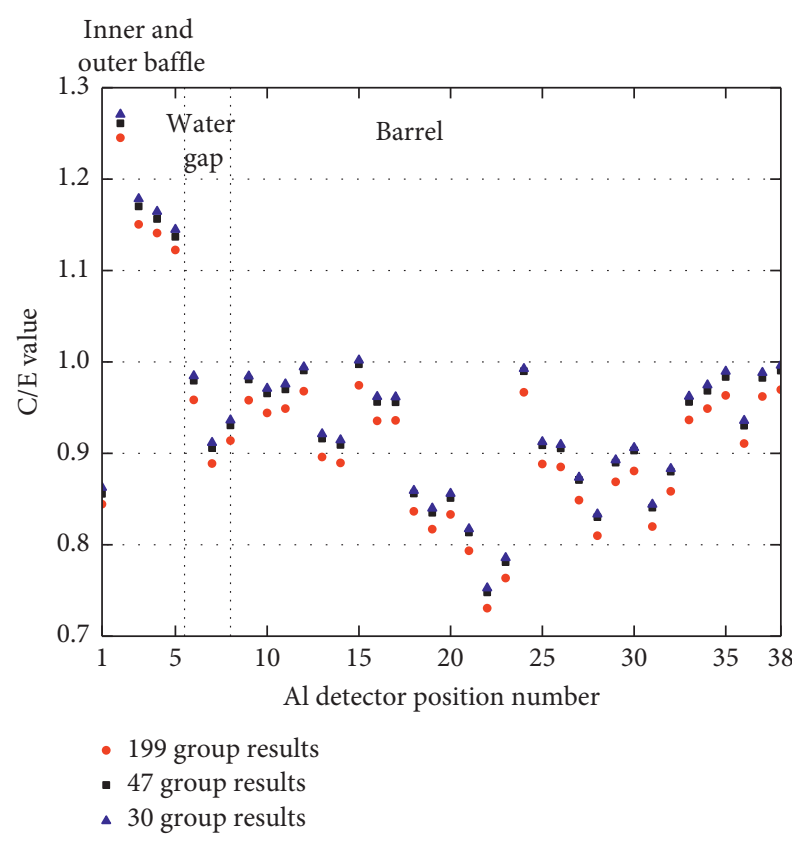

Figure 10: Comparison of group structure of the ${ }^{27} \mathrm{Al}(\mathrm{n}, \alpha)^{24} \mathrm{Na}$ detector.

than the unresolved resonance energy of most medium weigh nuclides, which may have weak resonance at high energy. Therefore, resonance processing has little influence on the calculation results.

4.3. Influence of Legendre Expansion Order on VENUS-3 Benchmark. Multigroup scattering cross sections are represented by Legendre polynomial expansion:

$$
\sigma_{s}\left(g^{\prime} \longrightarrow g, \Omega^{\prime} \longrightarrow \Omega\right)=\sum_{l=0}^{\infty} \frac{2 l+1}{4 \pi} \sigma_{s, l}\left(g^{\prime} \longrightarrow g\right) P_{l}\left(\mu_{0}\right),
$$

where $l$ is the Legendre expansion order and $\sigma_{s, \ell}\left(g^{\prime} \longrightarrow g\right)$ is high-order scattering cross section.

For different types of computational problems, different Legendre expansion order is needed to obtain more accurate transport calculation results. The higher the Legendre order is, the more accurately the anisotropic scattering model can be described [17].

To verify the effect of the Legendre expansion order for VENUS-3 benchmark, $P_{1}, P_{3}$, and $P_{5}$ scattering cross sections are used to calculate the benchmark. Figures 14-16 are the comparison of three detector results. The calculation results of the three detectors for the $\mathrm{P}_{3}$ and $\mathrm{P}_{5}$ expansion order are almost the same, and $\mathrm{P}_{1}$ results are higher than the other two results except at the fuel region. Therefore, the core calculation usually uses the $\mathrm{P}_{1}$ or $\mathrm{P}_{0}$ Legendre expansion order scattering sections and can even use diffusion calculation directly, which is accurate enough for the reactor core. However, for shielding calculation of equipment and materials outside the core, the $\mathrm{P}_{1}$ order scattering cross sections cannot exactly describe the anisotropic scattering of neutrons. The calculation results indicate that, for
VENUS-3 benchmark, calculation using $\mathrm{P}_{1}$ expansion scattering cross sections will cause large errors, especially for the ${ }^{27} \mathrm{Al}(\mathrm{n}, \alpha){ }^{24} \mathrm{Na}$ detector, and $\mathrm{P}_{3}$ expansion scattering cross sections are high enough for both accuracy and efficiency. For the shielding problem with higher energy of the neutron source, it may be necessary to use higher order scattering cross sections to describe the strong anisotropic scattering of neutrons in the material.

4.4. Influence of Transport Correction on VENUS-3 Benchmark. For the $S_{N}$ transport calculation method, using higher Legendre expansion order scattering cross sections can exactly describe the anisotropic scattering of neutrons, and more accurate results can be obtained. However, it will greatly increase the computation time. Therefore, in terms of $\mathrm{S}_{N}$ transport calculation, a particular choice of $\sigma_{g}^{S_{N}}$ gives rise to a "transport approximation" and various recipes are in use, as follows [16]:

Consistent-P transport approximation:

$$
\sigma_{g}^{S_{N}}=\sigma_{t 0 g}
$$

Diagonal (Diag) transport approximation:

$$
\sigma_{g}^{S_{N}}=\sigma_{t, N+1, g}-\sigma_{s, N+1, g} \longrightarrow g
$$

Bell-Hansen-Sandmeier (BHS) or extended transport approximation:

$$
\sigma_{g}^{S_{N}}=\sigma_{t, N+1, g}-\sum_{g^{\prime}} \sigma_{s, N+1, g^{\prime}} \longrightarrow g .
$$

These corrections require the $(N+l)$-th Legendre expansion order of the scattering cross sections to prepare a corrected $\mathrm{N}$-table set [18]. Both diagonal transport approximation and BHS transport approximation use high Legendre expansion order of the scattering cross sections to correct the low-order scattering cross sections. It can improve the precision of the transport calculation, especially for low Legendre expansion order calculation.

To verify the influence of the different transport calculation methods for VENUS-3 benchmark, the $\mathrm{P}_{1}$ and $\mathrm{P}_{3}$ scattering cross sections with and without transport correction are used to calculate the benchmark, respectively. Figures 17-19 are the comparison of three detector results with $\mathrm{P}_{1}$ scattering cross sections. For the ${ }^{58} \mathrm{Ni}(\mathrm{n}, \mathrm{p})^{58} \mathrm{Co}$ detector, results without transport corrections are higher than the other two transport correction results except at the fuel region. The results of BHS transport correction and diagonal transport correction are close to each other in most areas. For ${ }^{115} \operatorname{In}\left(\mathrm{n}, \mathrm{n}^{\prime}\right){ }^{115 \mathrm{~m}} \mathrm{In}$ and ${ }^{27} \mathrm{Al}(\mathrm{n}, \alpha)$ ${ }^{24} \mathrm{Na}$ detectors, results without transport correction are larger compared with the other two results. The results show that transport correction has a great influence on the calculation 


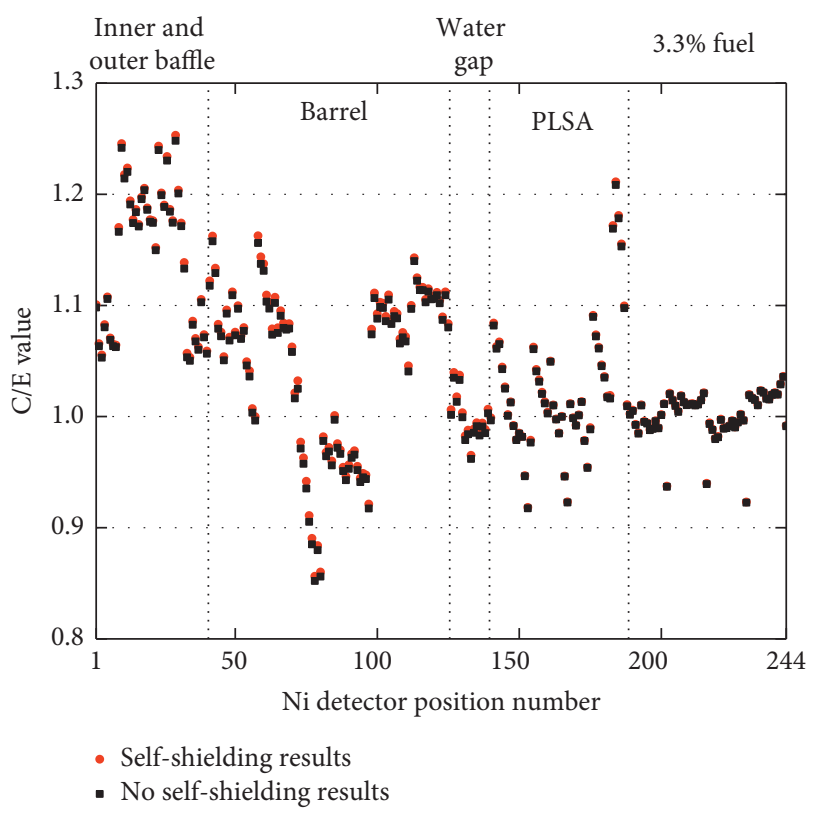

FIGURE 11: Comparison of self-shielding correction of the ${ }^{58} \mathrm{Ni}(\mathrm{n}, \mathrm{p})$ ${ }^{58}$ Co detector.

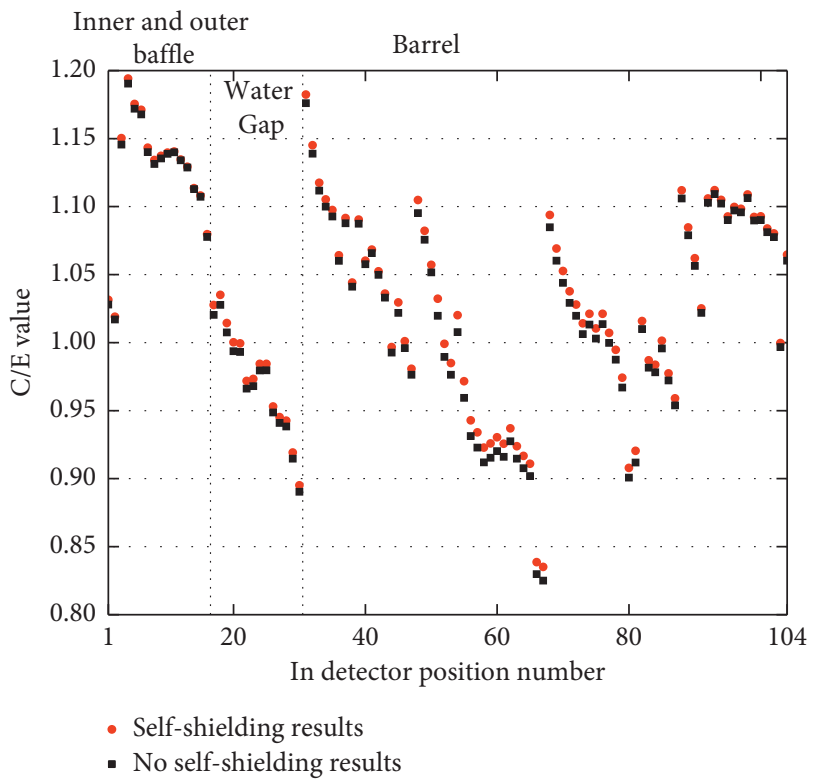

Figure 12: Comparison of self-shielding correction of the ${ }^{115} \operatorname{In}\left(\mathrm{n}, \mathrm{n}^{\prime}\right){ }^{115 \mathrm{~m}}$ In detector.

results of $\mathrm{P}_{1}$ expansion scattering cross-section results. Figures 20-22 are the comparison of three detector results with $\mathrm{P}_{3}$ expansion scattering cross sections. For all three detectors results, there is only a small difference in results with and without transport correction. The two transport correction results are almost identical in all regions. Therefore, both transport correction methods are appropriate for $\mathrm{P}_{3}$ calculation of VENUS-3 benchmark.

In order to verify which transport correction method is better for $\mathrm{P}_{1}$ calculation in VENUS-3 benchmark, the results with different transport corrections are compared.

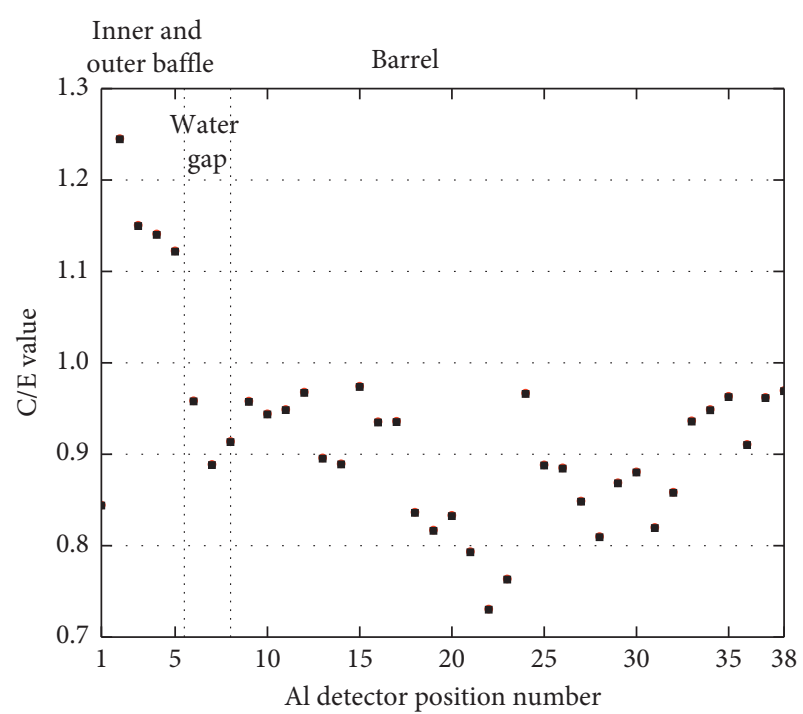

- Self-shielding results

- No self-shielding results

FIGURE 13: Comparison of self-shielding correction of the ${ }^{27} \mathrm{Al}(\mathrm{n}, \alpha)$ ${ }^{24} \mathrm{Na}$ detector.

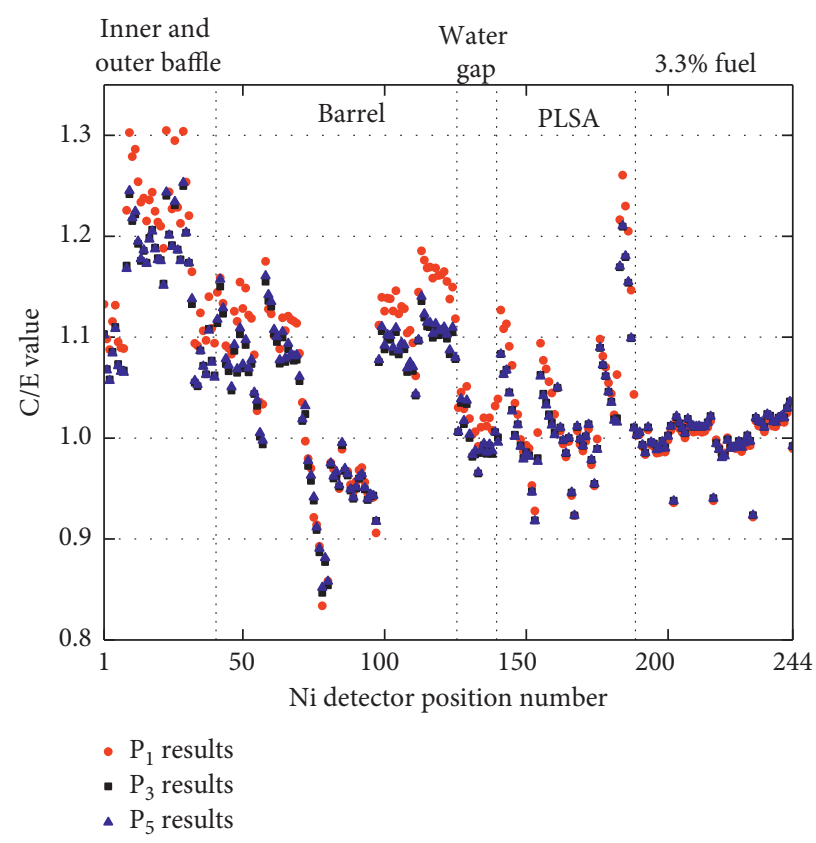

Figure 14: Comparison of Legendre expansion order of the ${ }^{58} \mathrm{Ni}(\mathrm{n}, \mathrm{p}){ }^{58}$ Co detector.

Figures 23-25 are the comparison of three detector results with $\mathrm{P}_{1}$ and $\mathrm{P}_{3}$ expansion scattering cross sections. For the ${ }^{58} \mathrm{Ni}(\mathrm{n}, \mathrm{p})$ ${ }^{58} \mathrm{Co}$ detector and ${ }^{27} \mathrm{Al}(\mathrm{n}, \alpha){ }^{24} \mathrm{Na}$ detector, $\mathrm{P}_{1}$ with diagonal transport correction results are closer to $\mathrm{P}_{3}$ results with $\mathrm{BHS}$ transport correction. For the ${ }^{115} \operatorname{In}\left(n, n^{\prime}\right)^{115 m}$ In detector, the opposite trend emerges. $\mathrm{P}_{1}$ with $\mathrm{BHS}$ transport correction results are very close to $\mathrm{P}_{3}$ results with $\mathrm{BHS}$ transport correction, and the difference between the $\mathrm{P}_{1}$ with diagonal transport correction results with other two results is huge. Therefore, although both methods use the high-order scattering cross 


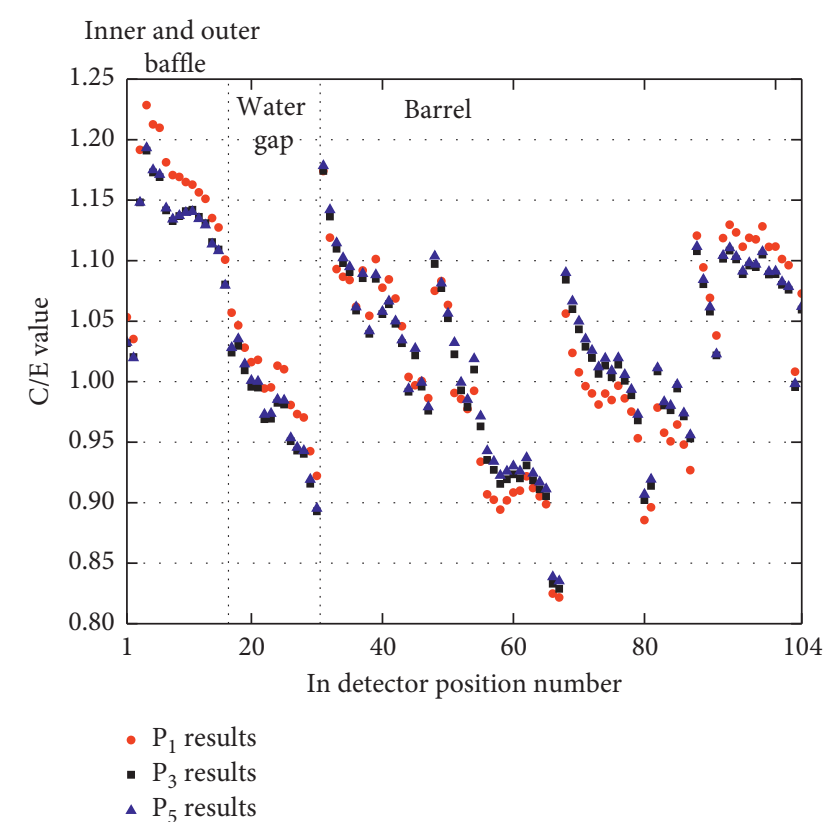

Figure 15: Comparison of Legendre expansion order of the ${ }^{115} \operatorname{In}\left(\mathrm{n}, \mathrm{n}^{\prime}\right){ }^{115 \mathrm{~m}}$ In detector.

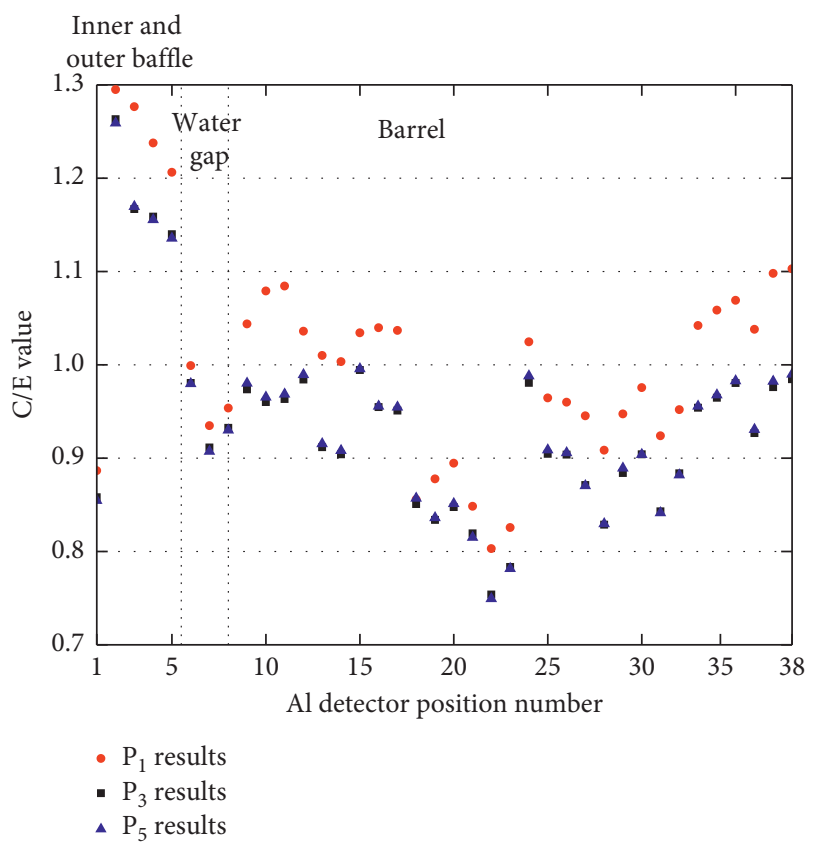

FIGURE 16: Comparison of Legendre expansion order of the ${ }^{27} \mathrm{Al}(\mathrm{n}, \alpha){ }^{24} \mathrm{Na}$ detector.

section to modify the low-order scattering cross section, no matter which transport correction method is used, it is impossible to calculate the benchmark accurately with $P_{1}$ Legendre

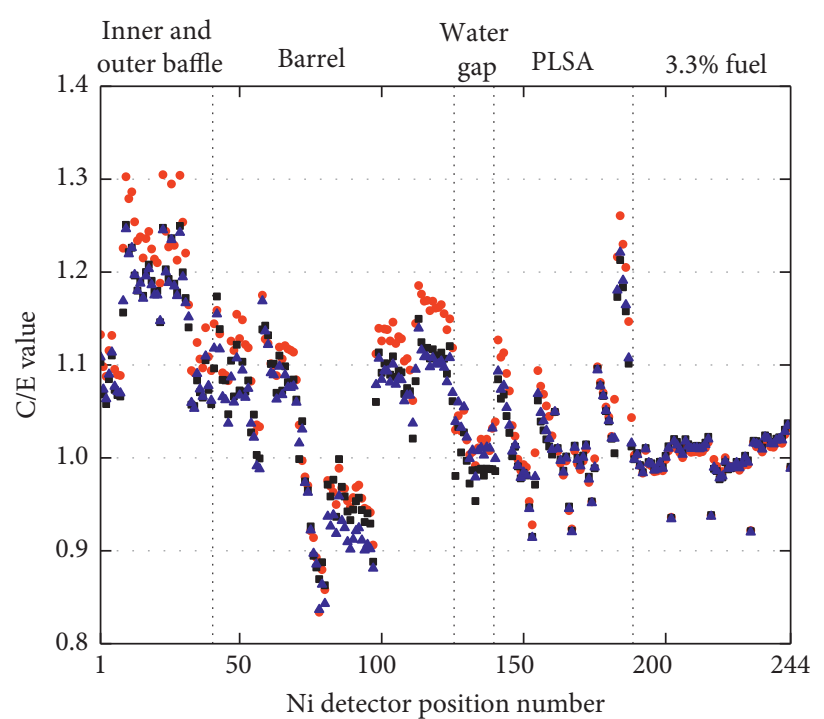

- $\mathrm{P}_{1}$ without transport correction

- $\mathrm{P}_{1}$ with BHS transport correction

$\Delta \mathrm{P}_{1}$ with diag transport correction

Figure 17: Comparison of $\mathrm{P}_{1}$ transport correction of the ${ }^{58} \mathrm{Ni}(\mathrm{n}, \mathrm{p}){ }^{58}$ Co detector.

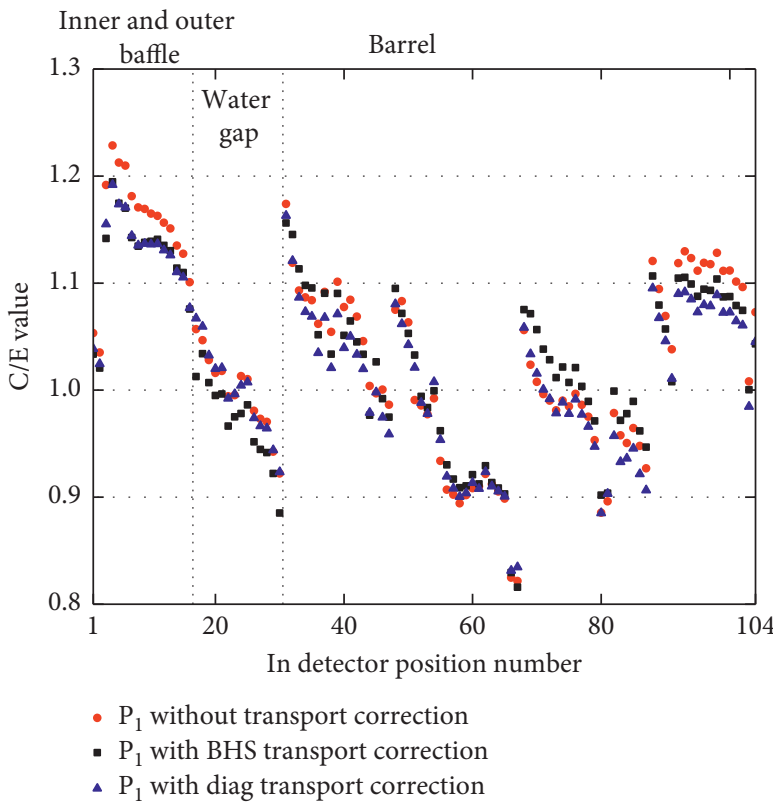

FIGURE 18: Comparison of $\mathrm{P}_{1}$ transport correction of the ${ }^{115} \operatorname{In}\left(\mathrm{n}, \mathrm{n}^{\prime}\right)$ ${ }^{115 \mathrm{~m}}$ In detector.

expansion order scattering sections. It is necessary to use $\mathrm{P}_{3}$ Legendre expansion order scattering sections for calculating VENUS-3 benchmark. 


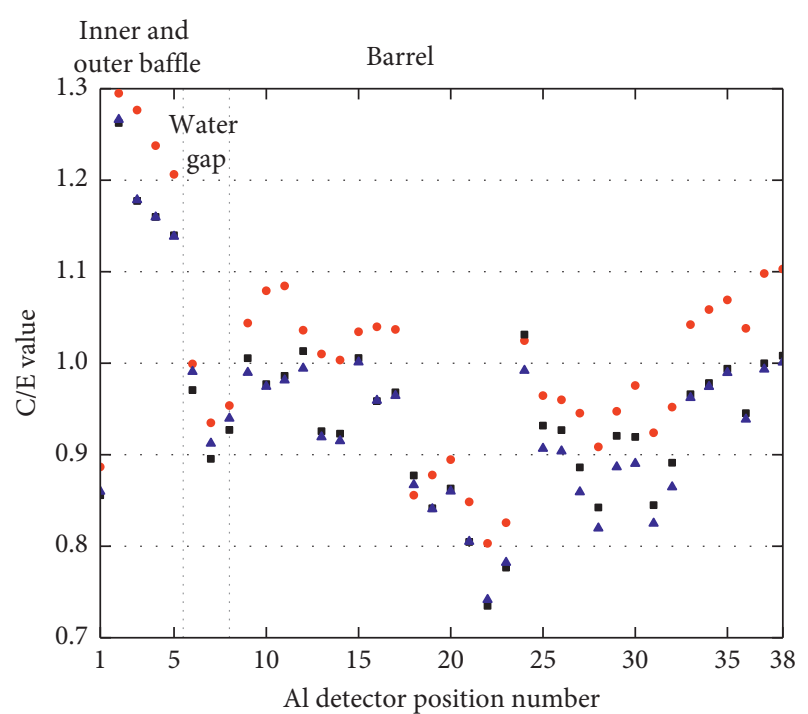

- $\mathrm{P}_{1}$ without transport correction

- $\mathrm{P}_{1}$ with BHS transport correction

- $\mathrm{P}_{1}$ with diag transport correction

FIGURE 19: Comparison of $\mathrm{P}_{1}$ transport correction of the ${ }^{27} \mathrm{Al}(\mathrm{n}, \alpha)$ ${ }^{24} \mathrm{Na}$ detector.

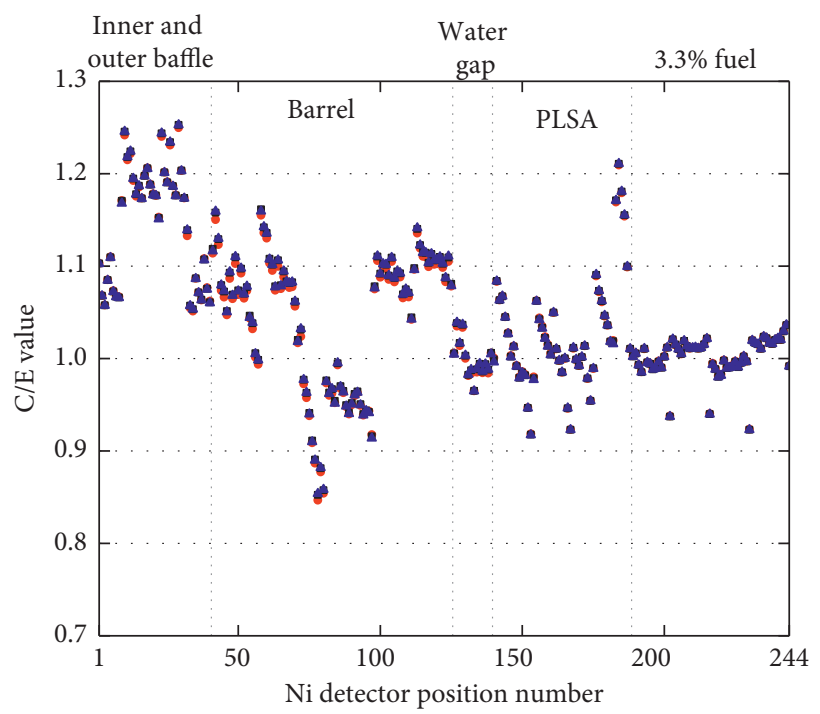

- $\mathrm{P}_{3}$ without transport correction

- $\mathrm{P}_{3}$ with BHS transport correction

- $\mathrm{P}_{3}$ with diag transport correction

Figure 20: Comparison of $\mathrm{P}_{3}$ transport correction of the ${ }^{58} \mathrm{Ni}(\mathrm{n}, \mathrm{p})$ ${ }^{58}$ Co detector.

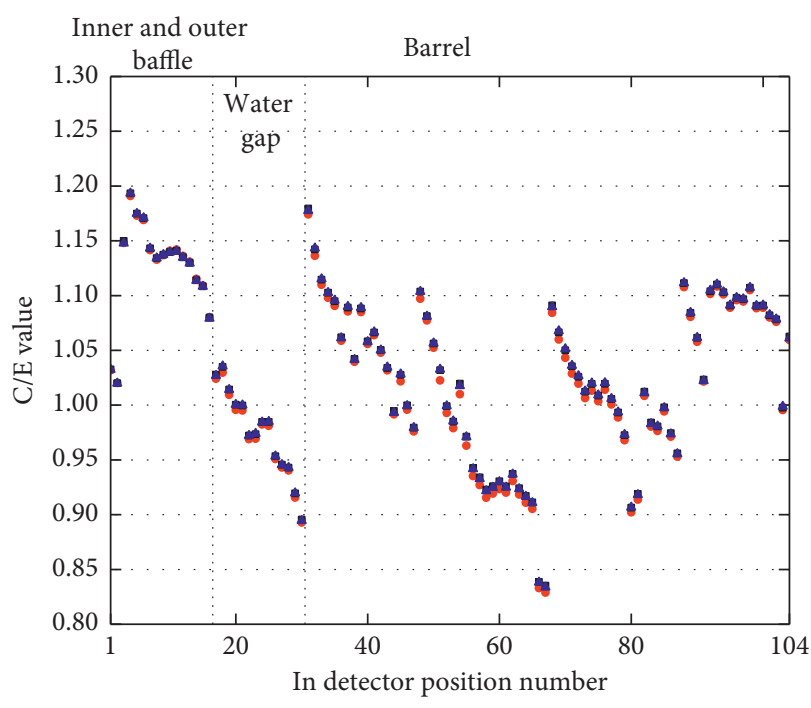

- $\mathrm{P}_{3}$ without transport correction

- $\mathrm{P}_{3}$ with BHS transport correction

$\triangle \mathrm{P}_{3}$ with diag transport correction

FIGURE 21: Comparison of $\mathrm{P}_{3}$ transport correction of the ${ }^{115} \operatorname{In}(\mathrm{n}, \mathrm{n}$ ') ${ }^{115 \mathrm{~m}}$ In detector.

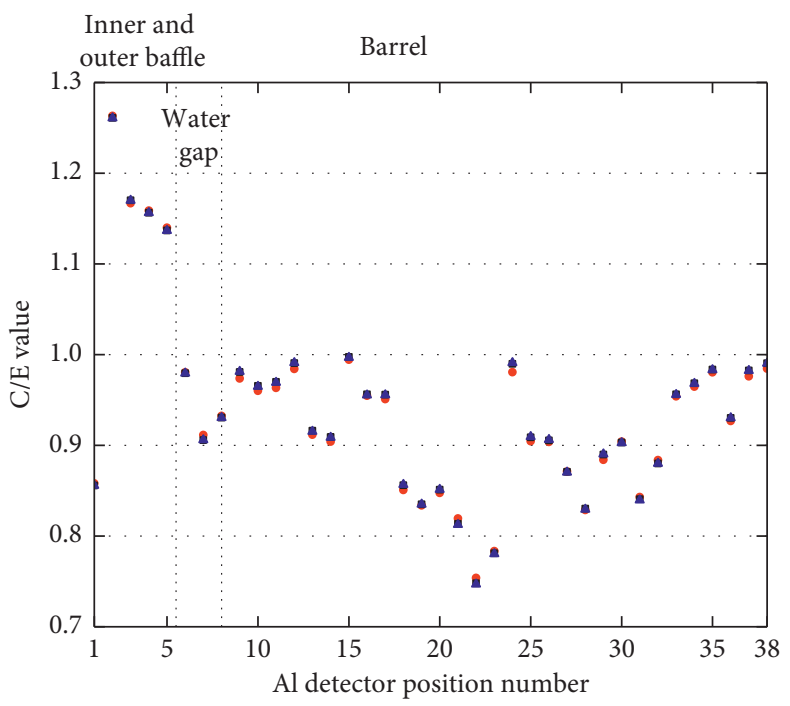

- $\mathrm{P}_{3}$ without transport correction

- $\mathrm{P}_{3}$ with BHS transport correction

- $\mathrm{P}_{3}$ with Diag transport correction

FIgURE 22: Comparison of $\mathrm{P}_{3}$ transport correction of the ${ }^{27} \mathrm{Al}(\mathrm{n}, \alpha)$ ${ }^{24} \mathrm{Na}$ detector. 


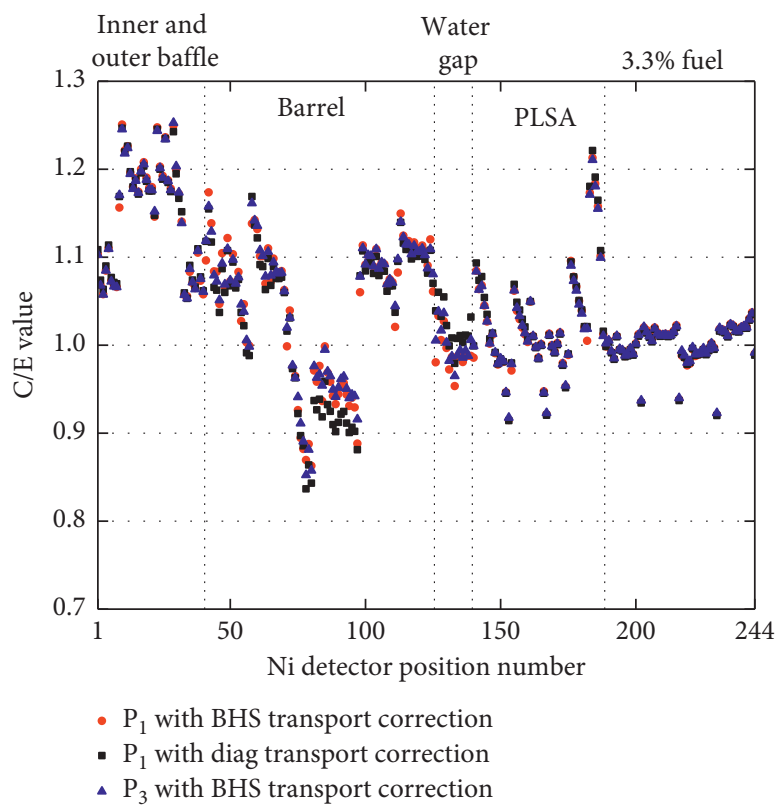

FIgURE 23: Comparison of $\mathrm{P}_{1}$ transport correction with $\mathrm{P}_{3}$ results of the ${ }^{58} \mathrm{Ni}(\mathrm{n}, \mathrm{p}){ }^{58} \mathrm{Co}$ detector.

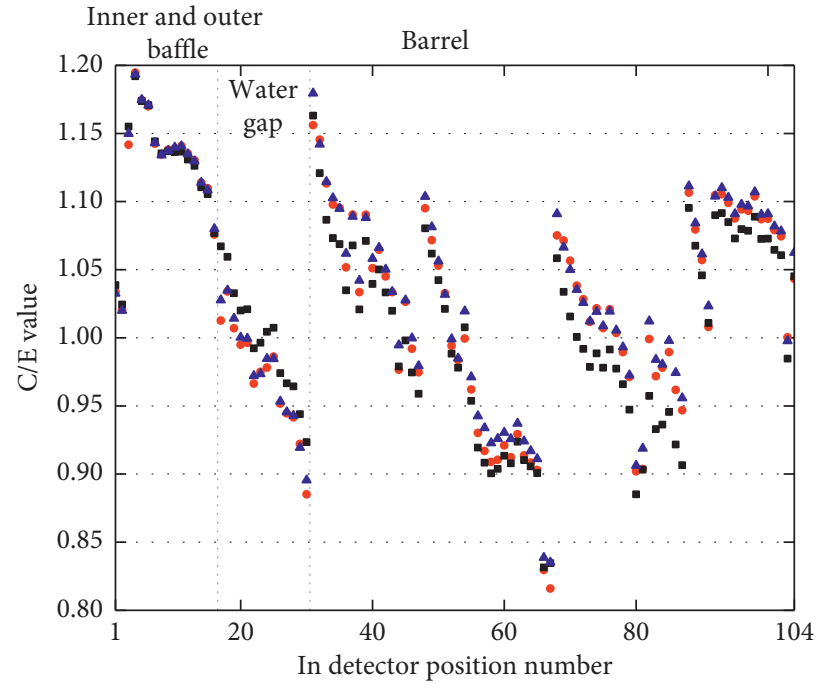

- $\mathrm{P}_{1}$ with BHS transport correction

- $\mathrm{P}_{1}$ with diag transport correction

- $\mathrm{P}_{3}$ with BHS transport correction

Figure 24: Comparison of $P_{1}$ transport correction with $P_{3}$ results of the ${ }^{115} \operatorname{In}\left(n, n^{\prime}\right){ }^{115 m}$ In detector. 


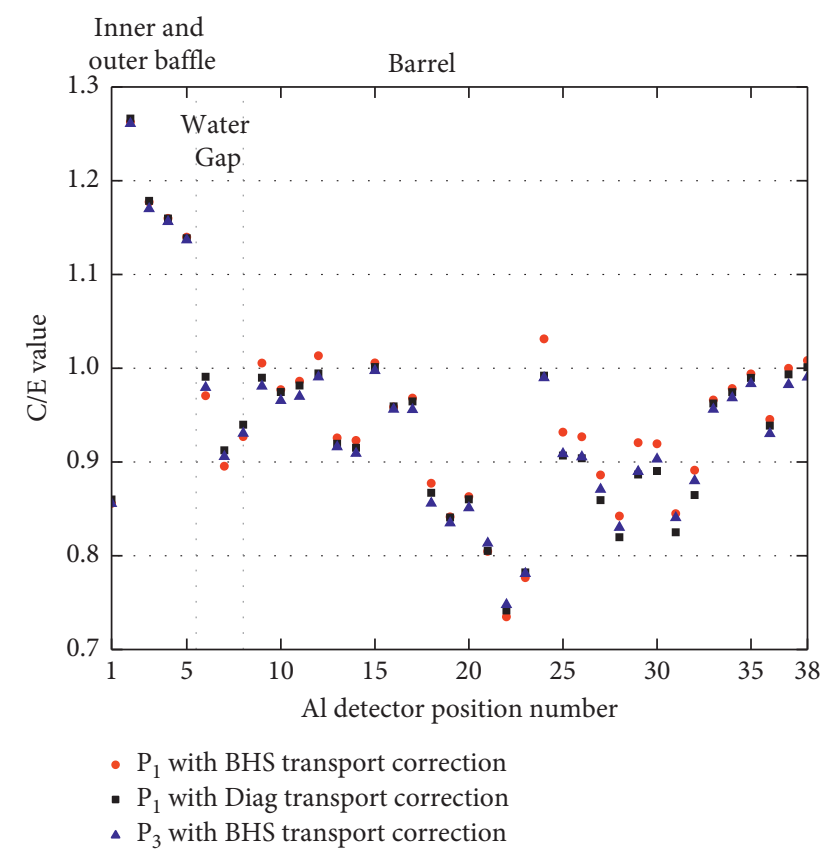

Figure 25: Comparison of $\mathrm{P}_{1}$ transport correction with $\mathrm{P}_{3}$ results of the ${ }^{27} \mathrm{Al}(\mathrm{n}, \alpha)^{24} \mathrm{Na}$ detector.

\section{Conclusion}

To verify the applicability of the CENDL-3.2 nuclear data library for PWR shielding calculation, VENUS-3 shielding benchmark is calculated by ARES with a detailed 3-D model. 199 neutron group structure multigroup cross-section library based on CENDL-3.2 is generated by NJOY. Multigroup cross-section library is processed using the ARES-MACXS module to generate multigroup working cross sections. The calculation results are compared with ENDF/B VII.0 nuclear data library results. The numerical results show that the equivalent fission flux rations (calculated/experimental) satisfy the requirement of engineering shielding calculation. And, the results of CENDL-3.2 nuclear data library have considerable accuracy compared with the ENDF/B VII.0 nuclear data library. It can be inferred that the CENDL-3.2 nuclear data library is suitable for the typical PWR shielding calculation.

Based on this multigroup cross-section library, the effects of various multigroup cross-section parameters on VENUS-3 benchmark calculation are analyzed. To improve calculation efficiency and ensure the calculation accuracy as much as possible, BUGLE-B7 broad-group structure is chosen for VENUS-3 benchmark calculation. Self-shielding correction is necessary for multigroup cross sections to improve the accuracy at resonance energy area, especially at unresolved resonance energy area. Deterministic transport calculation uses Legendre expansion scattering cross sections. The higher the Legendre expansion order is, the more accurate the results can be obtained, but the calculation time will also increase correspondingly. The comparison of the calculated results shows that $\mathrm{P}_{3}$ Legendre expansion order scattering cross sections are suitable for VENUS-3 benchmark. For low Legendre order calculation, different transport correction methods may have different effects on calculation results. For high Legendre order calculation, transport correction has less effect on calculation results. Although the higher order scattering cross section is used to modify the lower order scattering cross section, using $P_{1}$ scattering cross section cannot obtain the accurate transport calculation results. Through the analysis of the above multigroup cross-section parameters, the multigroup cross-section parameters that are suitable for VENUS-3 benchmark can be obtained, which can provide a valuable reference for engineering PWR shielding calculation.

\section{Data Availability}

The data used to support the findings of this study are included within the article.

\section{Conflicts of Interest}

The authors declare that there are no conflicts of interest.

\section{Acknowledgments}

This work was supported by the National Natural Science Foundation of China (Grant no. 11975097).

\section{References}

[1] E. E. Lewis and W. F. Miller, Computational Method of Neutron Transport, John Wiley \& Sons Inc, Hoboken, NJ, USA, 1983.

[2] G. C. Chen, W. T. Cao, B. Yu et al., "Neutron nuclear data evaluation of actinoid nuclei for CENDL-3.1," Chinese Physics C, vol. 36, 2012.

[3] S. W. Dean and Y. K. Lee, "Analysis of the VENUS3 PWR pressure vessel surveillance benchmark using TRIPOLI4.3 Monte Carlo code," Journal of Astm International, vol. 3, no. 10, 2006.

[4] M. Pescarini, R. Orsi, and T. Martinelli, Automatic Generation of 3D Fine Mesh Geometries for the Analysis of the VENUS-3 Shielding Benchmark Experiment with the TORT Code, ENEA, 2003.

[5] R. Maerker, P. Dhondt, L. Leenders, and A. Fabry, Analysis of the VENUS3 Experiments, Nuclear Energy in Central Europe, Europe, 1992.

[6] R. E. MacFarlane, D. W. Muir, Boicourt et al., The NJOY Nuclear Data Processing System: Version 2016. LAUR-17-20093, Los Alamos National Laboratory, USA, 2016.

[7] Y. Chen, B. Zhang, L. Zhang et al., "ARES: a parallel discrete ordinates transport code for radiation shielding applications and reactor physics analysis," Science and Technology and Nuclear Installations, vol. 2017, Article ID 2596727, 11 pages, 2017.

[8] L. Zhang, B. Zhang, P. Zhang et al., "Verification of ARES transport code system with TAKEDA benchmarks," Nuclear Instruments and Methods in Physics Research Section A: Accelerators, Spectrometers, Detectors and Associated Equipment, vol. 797, pp. 297-303, 2015.

[9] I. I. Bondarenko, Group Constants for Nuclear Reactor Calculations, Consultants Bureau, New York, USA, 1964. 
[10] N. M. Greene, BONAMI: Resonance Self- Shielding by the BONDARENKO Method, ORNL/TM-2005/39, BONAMI, Delhi, India, 2005.

[11] Members of OECD/NEA, Prediction of Neutron Embrittlement in Reactor Pressure Vessel: VENUS-1 and VENUS-3 Benchmarks, OECD/NEA, Paris, France, 2000.

[12] D. H. Kim, C. S. Gil, and Y. O. Lee, "Validation of an ENDF/BVII.0-Based neutron and photon shielding library in MATXSformat," Journal of Korean Physical Society, vol. 59, no. 3, pp. 1199-1202, 2011.

[13] M. Pescarini, R. Orsi, M. G. Borgia, and T. Martinelli, Enea Neutron Transport Analysis of the Venus-3 Shielding Benchmark Experiment - Preliminary Report, Centro Ricerche Bologna, Bologna, Italy, 2000.

[14] J. M. Risner, D. Wiarda, T. M. Miller et al., "Development and testing of the VITAMIN-B7/BUGLE-B7 coupled neutrongamma multigroup cross-section libraries," Journal of ASTM International, vol. 9, no. 5, 2012.

[15] J. M. Risner, Production and Testing of the VITAMIN-B7 FineGroup and BUGLE-B7 Broad-Group Coupled Neutron/ Gamma Cross-Section Libraries Derived from ENDF/B-VII.0 Nuclear Data, Oak Ridge National Laboratory, Oak Ridge, TN, USA, 2011.

[16] R. E. MacFarlane, TRANSX 2.15: A Code for Interfacing MATXS Cross-Section, Los Ala mos National Laboratory, New Mexico, USA, 1998.

[17] G. I. Bell, G. E. Hansen, and H. A. Sandmeier, "Multitable treatments of anisotropic scattering in s/sub $\mathrm{n} /$ multigroup transport calculations," Nuclear Science \& Engineering the Journal of the American Nuclear Society, vol. 28, 1967.

[18] T. Yamamoto, T. Takeda, Y. Sasaki, and Y. Saito, "Threedimensional transport correction in fast reactor core analysis," Journal of Nuclear Science and Technology, vol. 23, no. 10, pp. 849-858, 1986. 